\title{
DESAIN APLIKASI SENI POP ART PADA BUSANA READY TO WEAR DENGAN TEKNIK DIGITAL PRINTING
}

\author{
Nopiyani $^{1}$, Winwin Wiana ${ }^{2}$ \\ Pendidikan Tata Busana, Fakultas Pendidikan Teknologi dan Kejuruan, Universitas Pendidikan Indonesia \\ ${ }^{1}$ nopiyani82@upi.edu \\ ${ }^{2}$ winwinwiana@upi.edu
}

\begin{abstract}
Abstrak
Seni Pop Art atau Populer Art merupakan seni populer aliran seni dipengaruhi fenomena sosial maupun budaya yang berkembang di masyarakat. Kehadiran seni Pop Art pada tahun 1960-an di Amerika dan Inggris, budaya pada zaman itu mengaitkan unsur gaya/style yang diusungnya. Gaya Pop Art divisualisasikan pada bentuk karya dimanfaatkan oleh dunia industri khususnya desainer grafis Indonesia diwujudkan pada pakaian menargetkan anak muda sebagai calon konsumen, terlepas dari trend pengunaan teknik, material serta bentuk yang jadi sasaran produksi dalam dunia industri di Indonesia. Sumber ide pada penciptaan karya seni Pop Art menjadi suatu hal yang menarik menggunakan teknik digital print. Keunggulan teknik digital print adalah dapat menghasilkan hasil yang telah dibuat, komposisi warna menghasilkan visual hidup. Dalam penelitian ini mengembangkan teknik digital print dengan menggunakan karya seni Pop Art.
\end{abstract}

Kata Kunci: Seni Pop Art, Digital Printing, Ready to Wear

\begin{abstract}
Pop Art or Popular Art is a popular art whose art flow is influenced by social and cultural phenomena that develop in society. The presence of Pop Art in the 1960s in America and England, the culture of that era linked elements of style that it carried. Pop Art style is visualized in the form of works utilized by the industrial world, especially Indonesian graphic designers, which is realized in clothing targeting young people as potential consumers, regardless of trends in the use of techniques, materials and forms that are targeted for production in the industrial world in Indonesia. The source of ideas on creating Pop Art works becomes an interesting thing using digital print techniques. The advantage of digital print technique is that it can produce results that have been made, color compositions produce vivid visuals. In this study developing digital print techniques using Pop Art artwork.
\end{abstract}

Keyword: Pop Art, Digital Printing, Ready to Wear

\section{PENDAHULUAN}

Seiring perkembangan zaman, gaya hidup masyarakat dalam hal berpakaian mulai dari material, bentuk, teknik dan seni melalui gaya terapannya yang diciptakan oleh desainer di dalam dunia fesyen. Salah satu seni di dunia lahir gerakan seni yang dikenal dengan sebutan Pop Art berkembang pada tahun 1960-an di Amerika dan Inggris, gaya Pop Art kerap dijadikan karya-karya rancangan dalam beberapa karya desain grafis di Indonesia, karya tersebut diolah dari produk budaya massa, misalnya dalam desain grafis gaya/style merupakan salah satu aspek penting dalam sebuah rancangan (Oldach, 1995 : 106) dalam (Wardana, 2012). Gaya tersebut digunakan oleh para desainer grafis dengan cara memvisualisasikan di dalam kanvas ataupun seni grafis.

Perpaduan gaya dunia seni rupa, karya Pop Art merupakan suatu bentuk 
karya inovasi kreatif terletak pada semangat kebebasan, konteks yang berbeda, karakter bahkan ide/konsep desain melalui bahasa visual dalam cara mengkomunikasikannya yang dimanfaatkan oleh industri sebagai pemikat produk kaum muda. Industri fesyen khususnya dalam hal pakaian, pembuatan desain seni Pop Art umumnya dibuat menggunakan media cat dan kanvas, kini setiap negara berkembang karena adanya teknologi komputer yang digunakan. Pembuatan desain seni Pop Art diaplikasikan menggunakan teknologi digital.

Dikutif dari Suhersono, (2005) menjelaskan bahwa:

"Digital Printing merupakan salah satu teknik pencetakan secara digital ke media/bahan kain menggunakan printer yang langsung mencetak ke permukaan kain. Ada dua jenis digital printing pada kain polyester dan digital printing pada kain serat alam."

Dalam proses penciptaan suatu desain aplikasi seni Pop Art pada busana ready to wear dengan teknik digital printing, Penulis menggunakan gaya terapan seni itu sendiri meliputi aspek komposisi bentuk, motif dan warna sehingga menghasilkan tampilan visual yang menarik dan bisa menjadi suatu kebutuhan target market anak muda di masyarakat. Busana ready to wear merupakan busana siap pakai, juga memiliki standar untuk meningkatkan kuantitas keuntungan. Busana yang diwujudkan berupa Three pieces dengan model shirt dan celana Pallazo, bagian aksesoris berupa Boho sandals serta kain berbahan serat alam yaitu canvas import dipadukan dengan penggunaan warna muda (young).

Tampilan motif yang mengambil inspirasi dari karya seni Roy Lichtenstein aliran abstrak ekspresionis dengan teknik digital printing berpotensi untuk mengembangkan sebuah inovasi produk fesyen busana ready to wear tanpa melepas makna aslinya yaitu seni Pop Art itu sendiri. (Menurut Tjok, 2010) dalam (Vindyona \& Rosandini, 2018) motif tertentu memiliki suatu potensi untuk kebaruan dari bidang fesyen, karena motif adalah suatu karya yang tidak hanya memiliki nilai estetik, namun memiliki nilai makna.

(Efidra \& Siagian, 2018) pada penelitiannya, melihat adanya peluang dan potensi pemanfaatan bahan tweed untuk busana pada daerah beriklim tropis. Penelitian yang relevan ini yang berjudul "penerapan bahan tweed pada busana ready to wear" dimana produk fashion berupa busana berbahan tweed dan mix dengan bahan lainnya yang bertema simple classic. bentuk busana yang dibuat mengikuti ciri khas style klasik yang menunjukkan kesan yang elegant, rapi, dan stabil. busana yang diciptakan memiliki cuttingan yang simple, dengan jahitan yang rapi, dan warna yang tidak terlalu mencolok serta match dari atas sampai bawah.

Demikian tujuan dari penelitian ini adalah mengembangkan ilmu wawasan, kreativitas dan keterampilan selama proses perkuliahan di kampus. Penerapan teknik digital printing dilakukan melalui proses pencetakan warna motif pada kain serat alam yaitu canvas import, dengan motif yang terinspirasi dari seni Roy Lichtenstein aliran abstrak ekspresionis serta perancangan produk ready to wear memiliki nilai fungsi, estetika dan keunikan yang bisa diterima oleh usaha industri dan masyarakat luas.

Manfaat dari penyusunan ini sebagai informasi hasil penerapan desain aplikasi seni Pop Art pada busana ready to wear dengan teknik digital printing mengharapkan usaha industri dapat mengambil sisi dari seni trend motif, komposisi warna dan model busana yang dapat diterima oleh masyarakat khususnya penikmat fesyen dalam menerima seni yang ada di dunia.

Sejak 1960-an (Whiting, 1997:3) dalam (Dawami, 2017), kepantasan pop pada penikmat Pop Art telah di sajikan sebagai dasar-dasar penolakan dan sebagai motivasi untuk mempertahankannya. Para sejarawan seni, kritikus, dengan semangat menyalahkan, memberi pujian, dan 
menganalisis Pop Art yang memanipulasi gambar komersial dan menggunakannya, yang diambil dari budaya konsumen. Perpaduan Pop Art dengan budaya konsumen, dalam dan dari dirinya mungkin tidak menarik untuk diperhatikan maupun berkembang dari berbagai kritik; beberapa penulis dan orang yang menyukai pameran kemudian memiliki dokumentasinya, sebuah tradisi lama dari pergerakan Modern Art dengan referensi ke budaya konsumen didahului Pop Art.

\section{METODE PENELITIAN}

Metode penelitian yang digunakan oleh peneliti adalah menunjukan pada suatu kata, diwujudkan dalam benda, dilihat dari penggunaannya melalui wawancara, pengamatan, dokumentasi dan lainnya. Metodelogi penelitian yang digunakan dalam penulisan karya ilmiah ini adalah menggunakan metode kualitatif (Herdiansyah, 2010). Metode yang digunakan untuk pengumpulan data tersebut yaitu (1) Studi Literatur, (2) Wawancara, (3) Eksplorasi, (4) Dokumentasi, (5) Analisis SWOT, Keyword, Alur Perancangan Karya, Data Wawancara

\section{HASIL DAN PEMBAHASAN Hasil}

Pada tahap studi literatur menggunakan pengumpulan data dengan mempelajari beberapa jurnal dan sumber dari internet yang berhubungan dengan seni Pop Art. Selain itu dilakukannya tahap wawancara sebagai salah satu pengumpulan data ketika responden dan peneliti berada langsung bertatap muka dalam proses penyampaian informasi yang berhubungan dengan fakta, kepercayaan, perasaan, keinginan dan lain sebagainya. Dalam proses penelitian ini bersifat kualitatif karena tujuan wawancara adalah untuk mendapat informasi sebagai data yang diperlukan untuk membuat suatu yang sebaik mungkin untuk mencapai tujuan penelitian (Rosaliza, 2015).
Dalam metode ini, peneliti melakukan ekplorasi penentuan material bahan yang akan digunakan untuk pembuatan busana ready to wear menggunakan teknik digital printing di eksplorasi hasil akhir perwarnaan terhadap material tersebut. Metode ini dilakukan untuk menganalisis perancangan penelitian ke dalam tabel Analisis SWOT sebagai berikut:

Tabel 1. Analisis SWOT

\begin{tabular}{|c|c|c|}
\hline Internal & Strength & Weakness \\
\hline Eksternal & $\begin{array}{l}\text { 1. Busana } \\
\text { ready to } \\
\text { wear } \\
\text { menggunaka } \\
\mathrm{n} \text { gaya seni } \\
\text { Pop Art } \\
2 . \\
\text { Menggunaka } \\
\mathrm{n} \text { material } \\
\text { kain canvas } \\
\text { import } \\
3 \text {. } \\
\text { Menggunaka } \\
\mathrm{n} \text { model } \\
\text { busana } \\
\text { mengikuti } \\
\text { trend } \\
3 \text {. Warna } \\
\text { yang } \\
\text { digunakan } \\
\text { menggunaka } \\
\mathrm{n} \text { warna } \\
\text { muda } \\
\text { vintage }\end{array}$ & $\begin{array}{l}\text { 1. Desain } \\
\text { busana ready to } \\
\text { wear } \\
\text { mengutamakan } \\
\text { kaum anak } \\
\text { muda } \\
\text { 2. Bahan tidak } \\
\text { jatuh dan } \\
\text { terkesan kaku } \\
\text { 3. kekuatan } \\
\text { warna } \\
\text { mengahasilkan } \\
\text { warna muda } \\
\text { vintage }\end{array}$ \\
\hline $\begin{array}{l}\text { Opportun } \\
\text {-ity } \\
\text { (peluang) }\end{array}$ & $\begin{array}{c}\text { Strategi } \\
\text { S-O }\end{array}$ & $\begin{array}{c}\text { Strategi } \\
\text { W-O }\end{array}$ \\
\hline $\begin{array}{l}\text { 1. Sasaran } \\
\text { target } \\
\text { dalam } \\
\text { pemasaran } \\
\text { yaitu } \\
\text { kaum anak } \\
\text { muda } \\
\text { 2. Bisa } \\
\text { diikut } \\
\text { sertakan } \\
\text { dalam } \\
\text { pementasa } \\
\text { n busana }\end{array}$ & $\begin{array}{l}\text { Merancang } \\
\text { desain seni } \\
\text { pop art pada } \\
\text { busana ready } \\
\text { to wear } \\
\text { menggunaka } \\
\text { n model } \\
\text { Three Pieces }\end{array}$ & $\begin{array}{l}\text { Mengembangka } \\
\text { n desain } \\
\text { menggunakan } \\
\text { karya seni Roy } \\
\text { Lichtenstein } \\
\text { aliran abstrak } \\
\text { Ekspresionis }\end{array}$ \\
\hline
\end{tabular}




\begin{tabular}{|c|c|c|}
\hline Threat & $\begin{array}{l}\text { Strategi } \\
\text { S-T }\end{array}$ & Strategi W-T \\
\hline $\begin{array}{l}\text { 1. desain } \\
\text { Aplikasi } \\
\text { seni pop } \\
\text { art dibuat } \\
\text { kedalam } \\
\text { busana } \\
\text { ready to } \\
\text { wear } \\
\text { dengan } \\
\text { aksen } \\
\text { hiasan } \\
\text { berupa } \\
\text { perpadua } \\
\text { n warna } \\
\text { yang } \\
\text { sepadan } \\
\text { dan } \\
\text { pelengka } \\
\text { p busana } \\
\text { yaitu } \\
\text { boho } \\
\text { sandals }\end{array}$ & $\begin{array}{l}\text { Merancang } \\
\text { desain } \\
\text { busana ready } \\
\text { to wear } \\
\text { menggunaka } \\
\text { n material } \\
\text { canvas } \\
\text { import }\end{array}$ & $\begin{array}{l}\text { Mengembangka } \\
\mathrm{n} \text { desain } \\
\text { dipadukan } \\
\text { dengan warna } \\
\text { muda vintage } \\
\text { yang menjadi } \\
\text { salah satu ciri } \\
\text { khas seni yang } \\
\text { dimunculkan }\end{array}$ \\
\hline $\begin{array}{l}\text { Strategi } \\
\text { Utama }\end{array}$ & \multicolumn{2}{|c|}{$\begin{array}{l}\text { Mengembangkan desain aplikasi } \\
\text { seni Pop Art pada busana ready } \\
\text { to wear dengan menggunakan } \\
\text { material canvas import sebagai } \\
\text { bahan utama pembuatan busana, } \\
\text { dan warna yang dihasilkan } \\
\text { menggunakan teknik digital } \\
\text { printing }\end{array}$} \\
\hline
\end{tabular}

Berikut pemilihan keyword berdasarkan data dari analisa STP, SWOT, USP.

Keyword

Tabel 2. Keyword

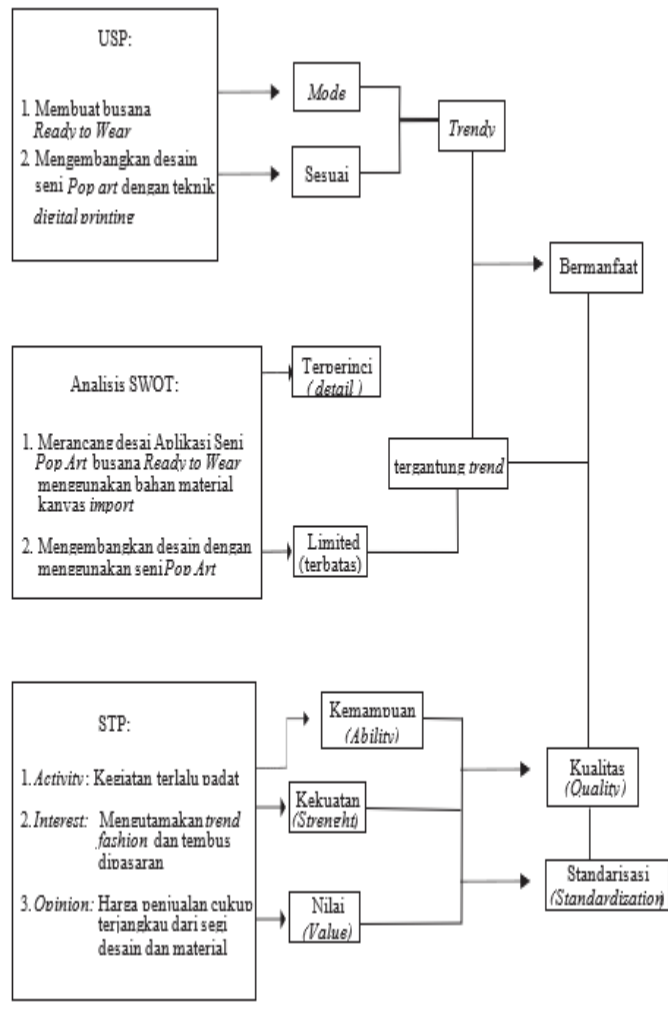

Tabel 3. Alur Perancangan Karya

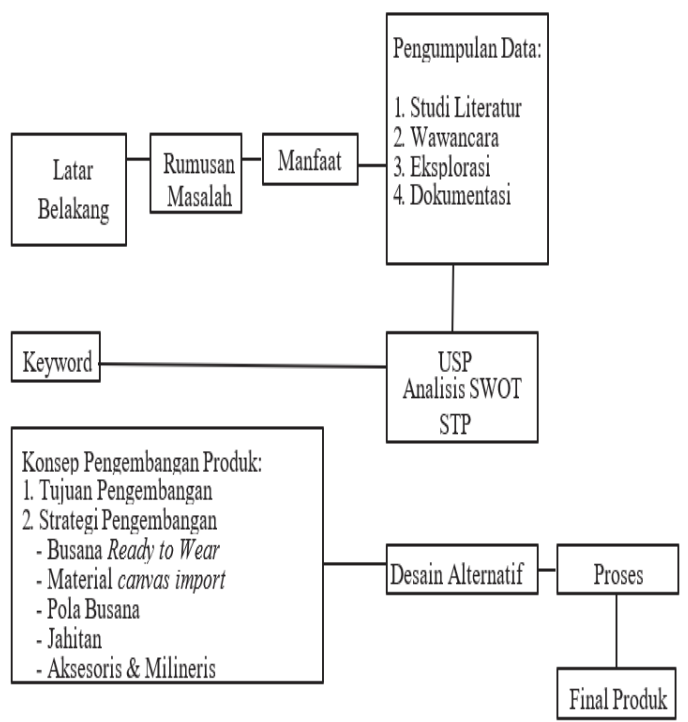


Tabel 4. Data Wawancara

\begin{tabular}{|c|c|c|c|}
\hline NO & $\begin{array}{c}\text { Data } \\
\text { wawanc } \\
\text {-ara }\end{array}$ & $\begin{array}{c}\text { Nara- } \\
\text { sumber }\end{array}$ & $\begin{array}{c}\text { Uraian } \\
\text { Data }\end{array}$ \\
\hline 1. & $\begin{array}{l}\text { Wawanc } \\
\text {-ara } \\
\text { online } \\
\text { pada } \\
\text { Mei } \\
2020 .\end{array}$ & $\begin{array}{l}\text { Asmi } \\
\text { Febrianti } \\
\text { CEO "Ido } \\
\text { Printing" }\end{array}$ & $\begin{array}{l}\text { Asmi } \\
\text { menyatakan } \\
\text { bahwa untuk } \\
\text { cetak printing } \\
\text { menggunakan } \\
\text { printer sublim } \\
\text { yaitu mesin } \\
\text { printer kain } \\
\text { yang } \\
\text { mencetak } \\
\text { gambar di } \\
\text { media } \\
\text { transfer paper } \\
\text { kemudian } \\
\text { gambar yang } \\
\text { sudah print di } \\
\text { transfer paper } \\
\text { tersebut } \\
\text { dipindahkan } \\
\text { ke kain } \\
\text { menggunakan } \\
\text { pemanas } \\
\text { (Heat Press) } \\
\text { sehingga } \\
\text { tintanya } \\
\text { menguap } \\
\text { (sublimasi) } \\
\text { berpindah } \\
\text { menempel } \\
\text { pada kain. } \\
\text { Kain yang } \\
\text { disarankan } \\
\text { menggunakan } \\
\text { 100\% } \\
\text { polyester agar } \\
\text { hasilnya } \\
\text { maksimal, } \\
\text { jika } \\
\text { kandungan } \\
\text { polyester ada } \\
\text { diantara } 50- \\
70 \% \text { hasilnya } \\
\text { akan gelap. }\end{array}$ \\
\hline
\end{tabular}

\section{Pembahasan}

Konsep Desain

Konsep pengembangan desain seni $P o p$ Art pada busana Ready to Wear ini untuk mempertahankan nilai seni pada zamannya, sehingga tidak dilupakan dari masa ke masa khususnya pada kaum modernisme. Sejalan dengan penelitian (Novella \& Rosandini, 2019), Dalam pengembangan produk desain seni $P o p$ Art pada busana Ready to Wear ini menggabungkan desain ilustrasi dengan hasil produk yang diwujudkan secara nyata pada kain polos diproses selama pewarnaan ke dalam mesin percetakan digital printing. Pengembangan desain ini menjadikan satu point of interest pada motif seni Pop Art yang diambil pada karya Roy Lichtenstein, karya tersebut menampilkan garis-garis tebal dan warna muda vintage seolah-olah diciptakan oleh reproduksi foto contohnya komik, lukisan dan lain sebagainya

Pada penelitian yang relevan oleh (Riyanto, Budiarjo, \& Mahmud, 2019) Perancangan kreatifnya memiliki tujuan kreatif yakni pengembangan produk untuk meningkatkan efisiensi. Demikian halnya pada pengembangan produk ini, memiliki nilai fungsi, estetika dan keunikan yang bisa diterima oleh usaha industri dan masyarakat luas.

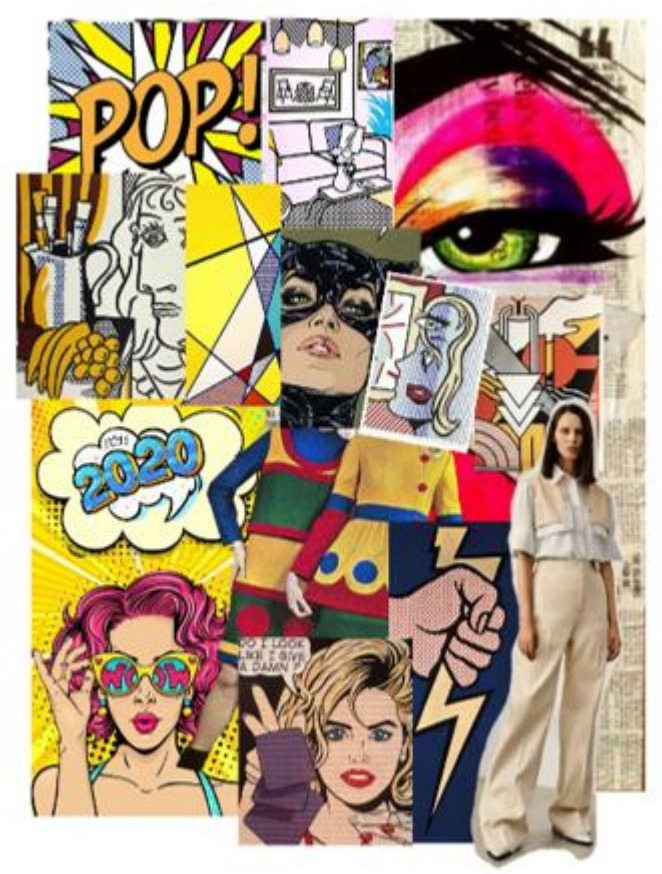

Gambar 1. Imageboard

Sumber: Olahan Peneliti, 2020 
Alternatif Desain

1. Tampak Depan

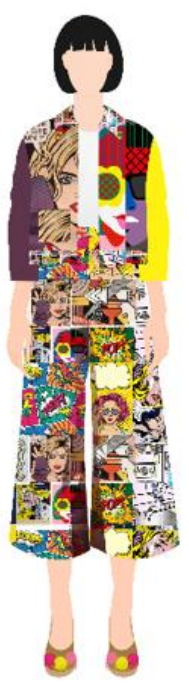

Gambar 2. Tampak Depan

Sumber: Olahan Peneliti, 2020

Desain seni Pop Art pada busana Ready To Wear, dengan konsep pada bagian badan terdapat T-Shirt round Collars, Patch, Donkey Jacket, sedangkan pada bagian bawah menggunakan Palazzo Pants, dan Boho Sandals. Selain itu, di bagian badan terdapat dua motif yang berbeda juga menggunakan variasi warna yang selaras dengan motif Pop Art juga menggunakan Boho Sandals pada pelengkap busana yang digunakan.

\section{Tampak Belakang}

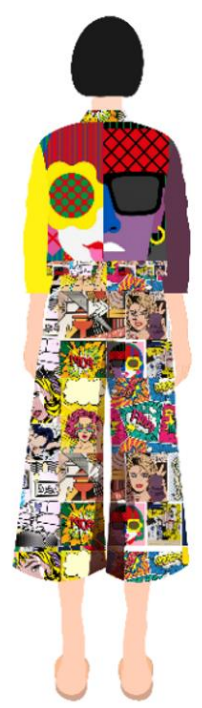

Gambar 3. Tampak Belakang Sumber: Olahan Peneliti, 2020.
Desain bagian tampak belakang menggunakan dua gambar menjadi satu kesatuan yang utuh yang memiliki makna filosofi dan nilai sosial yang tertuang pada busana Ready to Wear terhadap konsep karya si pencipta.

Gambar Pola Busana

1. Pola Dasar Bagian Badan

Ukuran Dasar M

Lingkar Badan: $88 \mathrm{~cm}$

Lingkar Pinggang: $73 \mathrm{~cm}$

Panjang Punggung: $37 \mathrm{~cm}$

Lebar Kerung Lengan: $52 \mathrm{~cm}$

Panjang Lengan: $30 \mathrm{~cm}$

Keterangan:

$\mathrm{A}-\mathrm{B}=1 / 2$ lingkar badan $+5=1 / 288+5=49$ $\mathrm{cm}$

$\mathrm{A}-\mathrm{E}=\mathrm{B}-\mathrm{F}={ }^{1} / 6$ lingkar badan $+5 \mathrm{~cm}=21,7$ $\mathrm{cm}$

$\mathrm{A}-\mathrm{C}=$ panjang punggung $=37 \mathrm{~cm}$

$\mathrm{E}-\mathrm{G}=1 / 6$ lingkar badan $+4,5 \mathrm{~cm}=19,1 \mathrm{~cm}$

$\mathrm{F}-\mathrm{H}=1 / 6$ lingkar badan $+3 \mathrm{~cm}=17,7 \mathrm{~cm}$

$\mathrm{A}-\mathrm{I}=1 / 20$ lingkar badan $+2,7 \mathrm{~cm}=7,1$

$\mathrm{B}-\mathrm{K}=\mathrm{A}-\mathrm{I}$

$\mathrm{B}-\mathrm{K}=\mathrm{B}-\mathrm{J}+1 \mathrm{~cm}=8,1 \mathrm{~cm}$

POLA DASAR BADAN WANITA SISTEM

SO-EN UKURAN M

SKALA 1:4

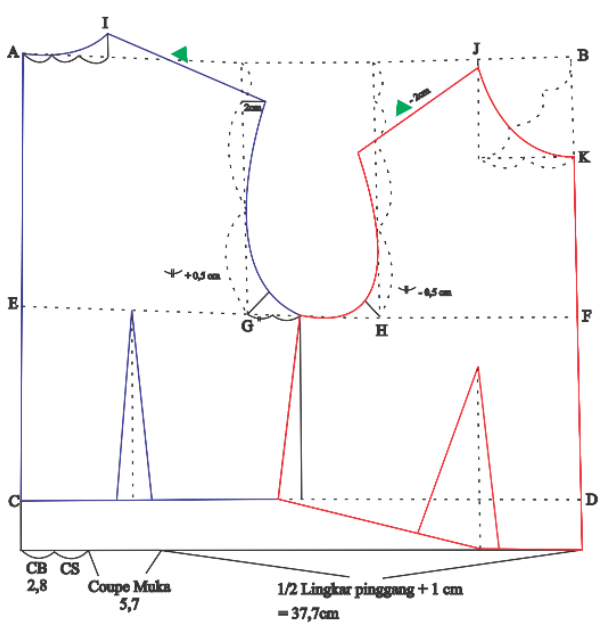

Pola Dasar Badan Wanita Sumber: Dokumen Pribadi, 2020. 
POLA PENGEMBANGAN BAGIAN BADAN

SKALA 1:4
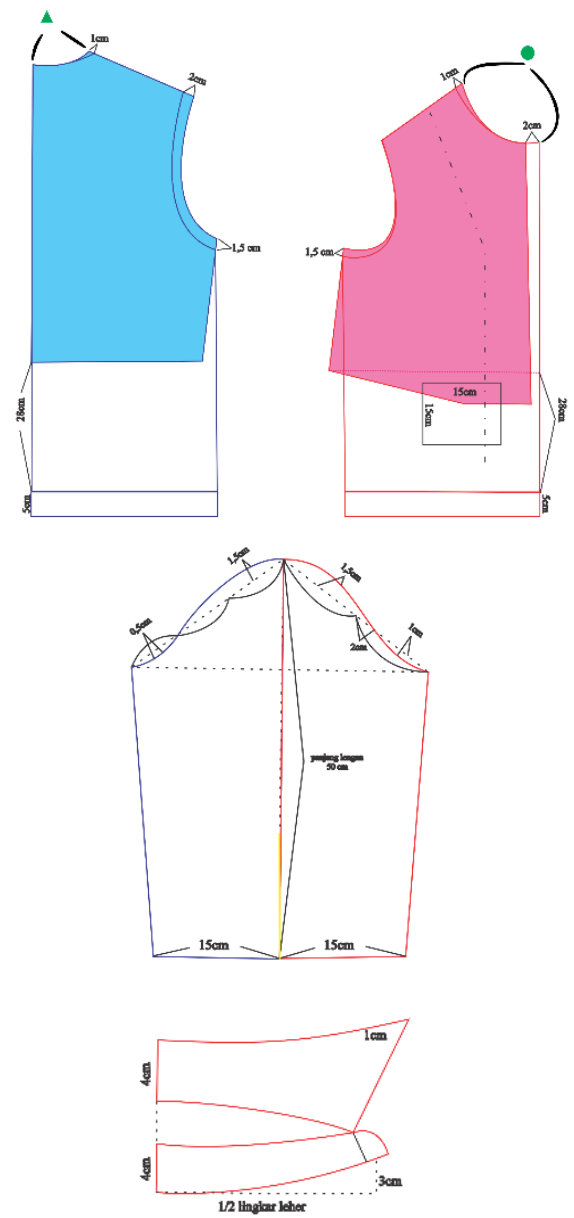

Pola Pengembangan Bagian Badan

Sumber: Dokumen Pribadi, 2020.

\section{Pola Dasar Bagian Celana}

Ukuran Dasar M

Lingkar Pinggang $=73 \mathrm{~cm}$

Panjang Celana $=80 \mathrm{~cm}$

Lingkar Panggul $=98 \mathrm{~cm}$

Lingkar Selangkangan $=65 \mathrm{~cm}$

Lingkar Paha $=66 \mathrm{~cm}$

Lingkar Lutut $=48 \mathrm{~cm}$

Lingkar Kaki $=36 \mathrm{~cm}$

Tinggi Panggul: $27 \mathrm{~cm}$

Keterangan:

Pola Dasar Celana Bagian Depan

$A-B=$ turun $1 \frac{1}{2} \mathrm{~cm}$

$\mathrm{B}-\mathrm{C}=$ Tinggi panggul

$\mathrm{B}-\mathrm{D}=$ Tinggi duduk

$\mathrm{D}-\mathrm{E}=$ turun 3 sampai 5

$\mathrm{B}-\mathrm{F}=$ panjang celana $=80 \mathrm{~cm}$

$B-J=1 / 4$ lingkar pinggang $+3 \mathrm{~cm}=21,25 \mathrm{~cm}$

$\mathrm{C}-\mathrm{L}=1 / 4$ lingkar panggul $+1 \mathrm{~cm}=25,5 \mathrm{~cm}$

$\mathrm{F}-\mathrm{M}=\mathrm{C}-\mathrm{L}=25,5 \mathrm{~cm}$

$\mathrm{M}-\mathrm{N}=3 \mathrm{~cm}$

$$
\begin{aligned}
& \mathrm{J}-\mathrm{N}=\mathrm{B}-\mathrm{F}=80 \mathrm{~cm} \\
& \mathrm{E}-\mathrm{O}=1 / 4(\mathrm{C}-\mathrm{L})+1 \mathrm{~cm}=7,3 \mathrm{~cm} \\
& \mathrm{D}-\mathrm{P}=1 \mathrm{~cm}
\end{aligned}
$$

Hubungkan titik B $-\mathrm{P}-\mathrm{O}, \mathrm{B}-\mathrm{J}-\mathrm{L}-\mathrm{N}$ dan $\mathrm{R}$ $-\mathrm{F}-\mathrm{N}$.

$\mathrm{Q}=\mathrm{E}-\mathrm{O}=7,3 \mathrm{~cm}$

$\mathrm{Q}-\mathrm{R}=1 \frac{1}{1 / 2 \mathrm{~cm}}$

$\mathrm{B}-\mathrm{H}=71 / 2 \mathrm{~cm}$

$\mathrm{H}-\mathrm{I}=3 \mathrm{~cm}$

$\mathrm{H}-\mathrm{K}=$ panjang kupnat $=11 \mathrm{~cm}$

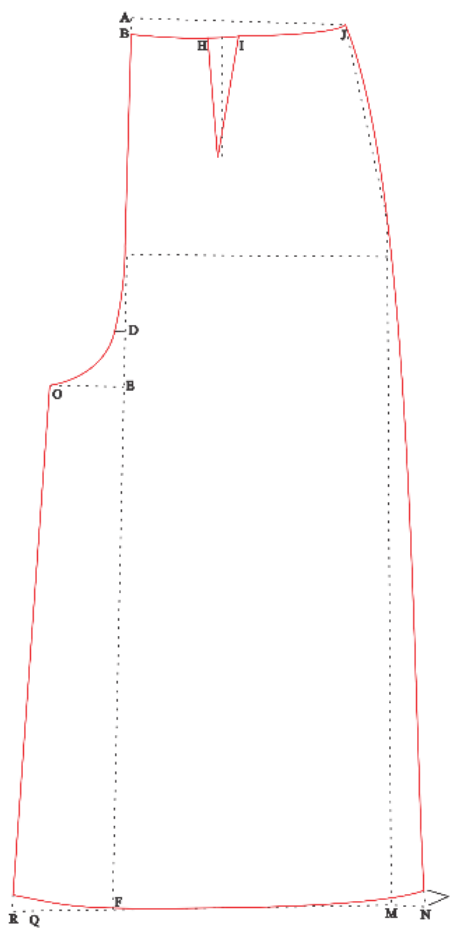

Pola Dasar Celana Bagian Depan Sumber: Dokumen Pribadi, 2020.

Pola Dasar Celana Bagian Belakang

$\mathrm{A}-\mathrm{B}=$ turun $1 \frac{1}{2} \mathrm{~cm}$

$\mathrm{B}-\mathrm{C}=$ Tinggi panggul

$\mathrm{B}-\mathrm{D}=$ Tinggi duduk

$\mathrm{D}-\mathrm{E}=$ turun 3 sampai 5

$\mathrm{B}-\mathrm{F}=$ panjang celana $=80 \mathrm{~cm}$

$\mathrm{B}-\mathrm{J}=1 / 4$ lingkar pinggang $+3 \mathrm{~cm}=21,25 \mathrm{~cm}$

$\mathrm{C}-\mathrm{L}=1 / 4$ linggal panggul $-1 \mathrm{~cm}=23,5 \mathrm{~cm}$

$\mathrm{F}-\mathrm{M}=\mathrm{C}-\mathrm{L}=25,5 \mathrm{~cm}$

$\mathrm{M}-\mathrm{N}=3 \mathrm{~cm}$

$\mathrm{D}-\mathrm{P}^{\mathrm{I}}=2 \mathrm{~cm}$

$\mathrm{J}-\mathrm{N}=\mathrm{B}-\mathrm{F}=80 \mathrm{~cm}$

$\mathrm{E}-\mathrm{O}=\mathrm{E}-\mathrm{O}($ pola depan $)=\mathrm{O}-\mathrm{O}^{\mathrm{I}}=4 \mathrm{~cm}$

$\mathrm{F}-\mathrm{Q}=\mathrm{E}-\mathrm{O}=7,3 \mathrm{~cm}$

$\mathrm{Q}-\mathrm{Q}^{\mathrm{I}}=4 \mathrm{~cm}$

$\mathrm{Q}^{\mathrm{I}}-\mathrm{R}=1 \frac{1}{2} \mathrm{~cm}$

Hubungkan titik B $-\mathrm{P}^{\mathrm{I}}-\mathrm{O}^{\mathrm{I}}-\mathrm{R}, \mathrm{B}-\mathrm{J}-\mathrm{L}-\mathrm{N}$

dan $\mathrm{R}-\mathrm{F}-\mathrm{N}$.

B- $\mathrm{H}=1 / 10$ lingkar pinggang $=7,3 \mathrm{~cm}$ 
$\mathrm{H}-\mathrm{I}=$ lebar kupnat $3 \mathrm{~cm}$

$\mathrm{H}-\mathrm{K}=$ panjang kupnat $11 \mathrm{~cm}$

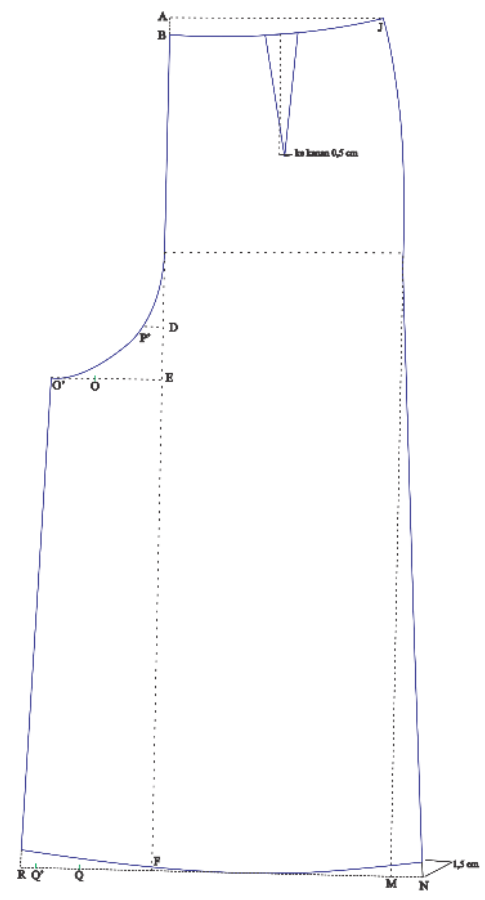

Pola Dasar Celana Bagian Belakang Sumber : Dokumen Pribadi, 2020.

Final Produk

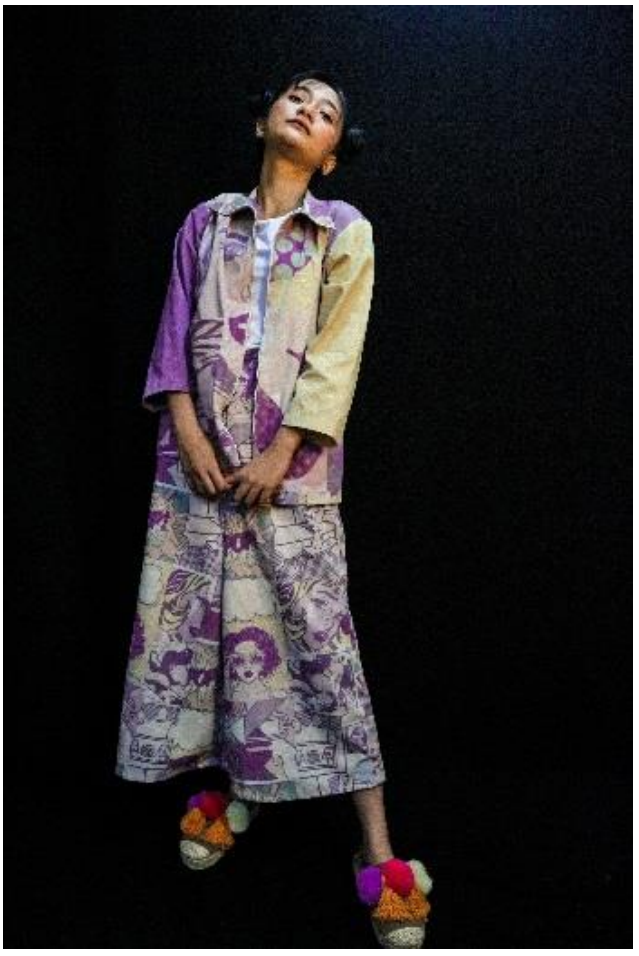

Gambar 4. Visualisasi Desain Busana (Sumber: Penulis, 2020)

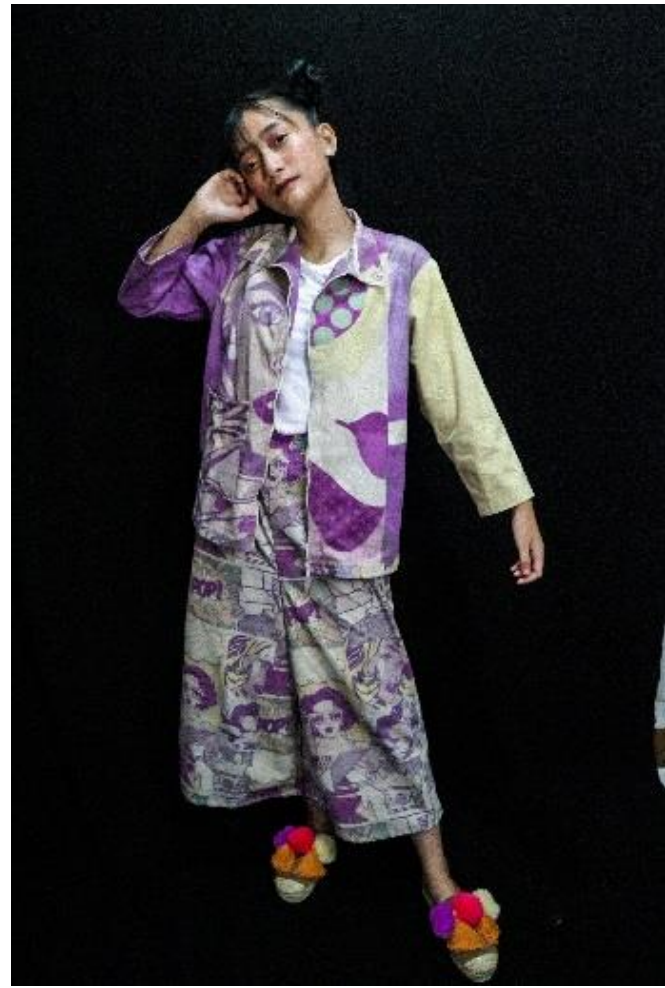

Gambar 5. Visualisasi Desain Busana (Sumber: Penulis, 2020)

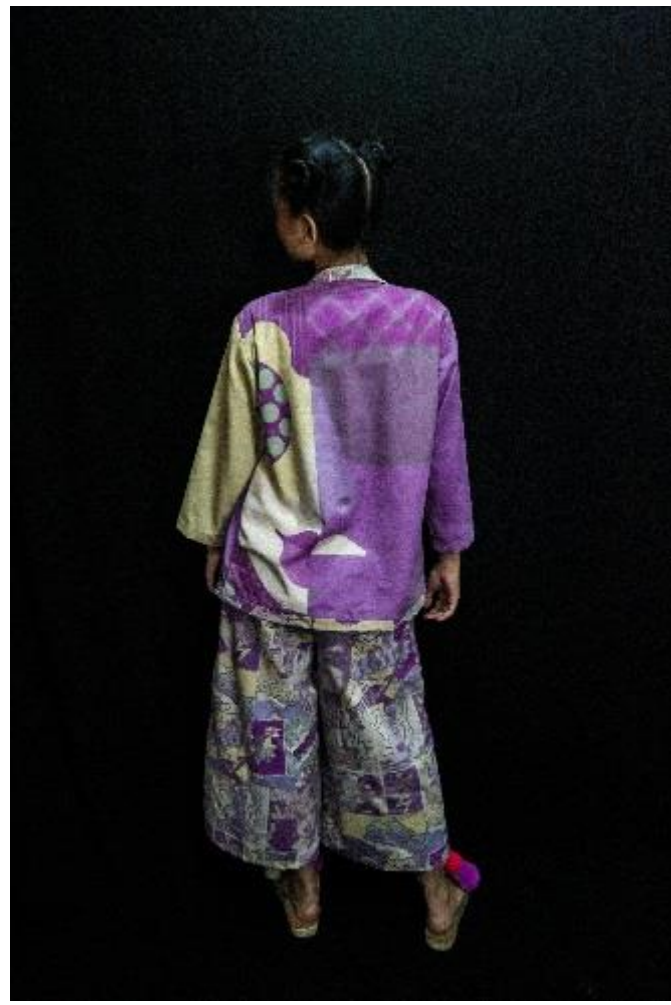

Gambar 6. Visualisasi Desain Busana (Sumber: Penulis, 2020) 


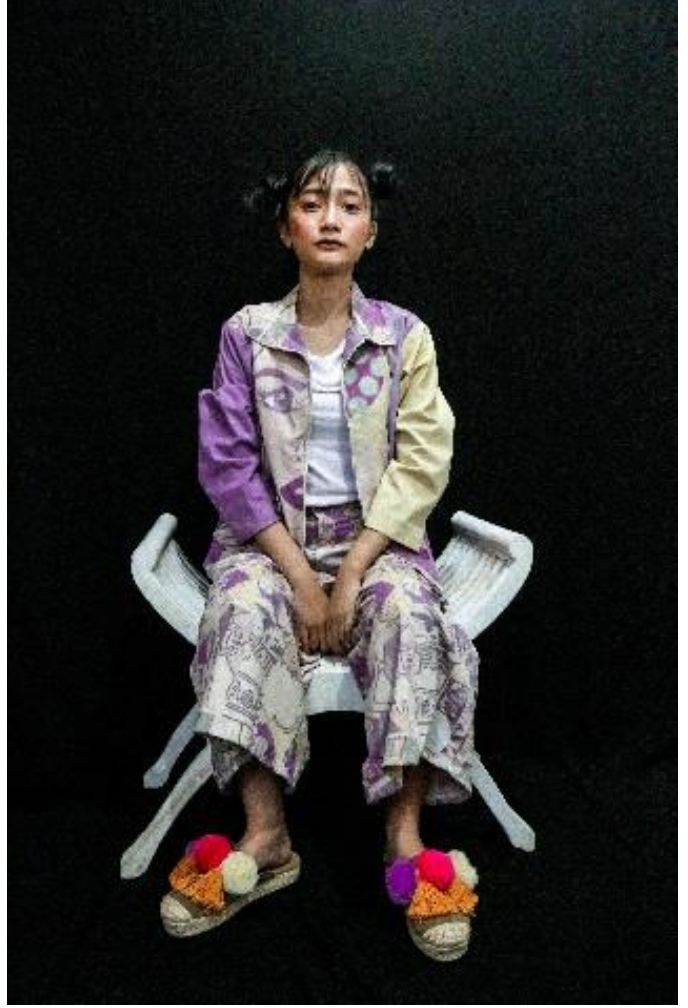

Gambar 7. Visualisasi Desain Busana (Sumber: Penulis, 2020)

\section{SIMPULAN DAN SARAN Kesimpulan}

Berdasarkan penelitian yang telah dilakukan, dapat disimpulkan bahwa:

1 Desain tampak depan dan belakang pada busana Ready to Wear, memiliki perbedaan pada desain tersebut dilihat dari model dan penempatan desain Pop Art.

2 Memiliki model Three Pieces yaitu menggunakan T-Shirt Round Collars, Patch, Donkey Jacket, sedangkan pada bagian bawah menggunakan Palazzo Pants, dan Boho Sandals. Busana tersebut memiliki Fungsi dan nilai estetis dalam pemakaian maupun model peragaan busana.

3 Material yang digunakan menggunakan bahan Canvas Import sesuai dengan bentuk model busana Ready To Wear, memiliki karakteristik tebal, kusut, kaku, namun terasa nyaman saat dipakai, dan bahan canvas import memiliki daya serap cukup baik.

4 Hasil cetak printing pada bahan canvas import mengalami kekurangan warna karena bahan tidak sepenuhnya $100 \%$ berbahan serat polyester. Seperti bahan Organza, Tafetta, Satin, Katun Ima, Voile, Scuba, Trulle, dan jenis kain lainnya. Mesin yang digunakan Printer Sublime yaitu proses cetak printing menggunakan cara transfer paper kemudian di press dengan tingkat tertentu.

\section{Saran}

Berdasarkan hasil pembahasan peneliti menyadari masih banyak kekurangan dalam proses desain aplikasi seni Pop Art pada busana Ready to Wear dengan teknik digital priting, jauh dari kata sempurna. Beberapa saran untuk meningkatkan agar lebih baik yaitu:

1. Pemilihan cetak printing harus disesuaikan sesuai jenis pemilihan kain, agar proses produksi selaras dengan desain.

2. Hasil pewarnaan pada bahan canvas import kurang karena mengandung $100 \%$ serat alam, sedangkan mesin yang dipakai pada cetak printing menggunakan printing sublime yang sepenuhnya $100 \%$ berbahan serat polyester.

3. Dalam perancangan desain, material, warna meningkatkan kenyamanan dalam proses produksi seperti tekstur dan kepadatan kain.

\section{DAFTAR PUSTAKA}

Dawami, A. K. (2017). Pop Art di Indonesia. Jurnal Desain, 4(03), 143. https://doi.org/10.30998/jurnaldesain.v4i0 3.1356

Efidra, M., \& Siagian, M. C. A. (2018). Penerapan Bahan Tweed Pada Busana Ready To Wear. EProceedings of Art \& Design, 5(3).

Herdiansyah, H. (2010). Metodologi penelitian kualitatif untuk ilmu-ilmu sosial. Jakarta: Salemba Humanika, 8.

Novella, Y., \& Rosandini, M. (2019). PERANCANGAN MOTIF TERINSPIRASI DARI VISUALISASI MONUMEN PERJUANGAN RAKYAT JAWA BARAT UNTUK BUSANA READY-TO-WEAR. ATRAT: Jurnal Seni Rupa, 7(1).

Riyanto, D. Y., Budiarjo, H., \& Mahmud, F. F. (2019). Pengembangan Desain Produk Tas Kuliah Yang Efisien Bagi Mahasiswa Desain Di Stikom Surabaya. Candrarupa: Journal of Art, Design, and Media, 1(1), 
7-14.

Rosaliza, M. (2015). Wawancara, Sebuah interaksi komunikasi dalam penelitian kualitatif. Jurnal Ilmu Budaya, 11(2)

Suhersono, H. (2005). Desain bordir motif geometris. Jakarta: PT. Gramedia Pustaka Utama.

Vindyona, S. P., \& Rosandini, M. (2018).

Pengolahan Motif Dengan Inspirasi Pola Garis Alam Yang Diaplikasikan Pada Busana Ready-to-wear. EProceedings of Art \& Design, 5(3).

Wardana, K. N. H. (2012). Gaya Pop Art pada Karya Desain Grafis di Indonesia. PRASI, $8(14)$.

Wawancara:

Febrianti, A. (2020, April 30)

Pemilik Ido Printing JJ. Textile Printing Jakarta. (Nopiyani, Interview).

Riffai, M. (2020, April 29) Design Graphic

Creative Enthusiast. (Nopiyani, Interview)

\section{Sumber dari Internet:}

Karya seni Roy Lichtenstein aliran Pop Art (en.wikipedia.org/Roy_Lichtenstein/pada tanggal 12 maret 2020 pukul 4:57)

(Pinterest.com/RoyLichtenstein/pada tanggal 15 April 2020 pukul 3:29)

(Pinterest.com/PopArtcomic/pa-da tanggal 15 April 2020 pukul 3:57) 